agencies. Soc Sci Med. 2010 Mar;70(5): 643-7. doi.org/10.1016/j. socscimed.2009.09.002.

27. Blackwell, T. The selling of OxyContin. National Post. 2011 Nov 12 [cited 2020 Feb 26]. Available from: https://nationalpost.com/news/canada/ the-selling-of-oxycontin

28. Crowe K. Opioid conflict-of-interest controversy reveals extent of big pharma's ties to doctors. CBC. 2017 May 19 [cited 2020 Feb 26]. Available from: https://www.cbc.ca/news/health/opioid-painphilpott-mcmaster-university-purdue-pharma-drug-industryconflict-1.4121956

29. Wong-Rieger D. Patient participation in HTA: evidence of real change? In Facey KM, Hanson HP, Single ANV, editors. Patient involvement in health technology assessment. Singapore: Springer Nature; 2017:373-80.

30. White MA. brief history of heckling. Guardian. 2006 Apr 28[cited 2020 Feb 26]. Available from: https://www.theguardian.com/politics/2006/ apr/28/past.labour.

31. Lehoux P, Blume S. Technology assessment and the sociopolitics of health technologies. J Health Polit Policy Law. 2000 Dec;25(6):10831120. doi.org/10.1215/03616878-25-61083

32. Abramson J. What will the Cochrane brand stand for? [Book review of Death of a whistleblower and Cochrane's moral collapse]. Indian J Med Ethics. 2019 Jul-Sep [cited 2020 Feb 26]; 4(3): 245-7. doi.10.20529/ IJME.2019.032 Available from: https://ijme.in/articles/what-will-thecochrane-brand-stand-for/

33. Pellerin R. Conspiracy of hope: The truth about breast cancer screening Fredericton, NB: Goose Lane Editions; 2018.

34. Wright CJ. Breast cancer screening: a different look at the evidence. Surgery. 1986. 100:594-7.

35. Banta DH, Thacker SB. Electronic fetal monitoring: lessons from a formative case of health technology assessment. Int J Technol Assess Health Care. 2002; 18(4):762-70. doi.10.1017/S0266462302000570
36. Lenzer J. Lay campaigners for prostate screening are funded by industry. BMJ. 2003 Mar 29; 326:680. doi: 10.1136/bmj.326.7391.680

37. Pharmaphorum. Patient opinion leaders: the new KOLs for pharma? UK: Pharmaphorum Premium Media. 2014.

38. Moynihan R. Key opinion leaders: independent experts or drug representatives in disguise? BMJ. 2008 Jun 21; 336(7658):1402-3. doi: 10.1136/bmj.39575.675787.651

39. Carlat D. Dr. Drug Rep. New York Times Magazine. 2007 Nov 25[cited 2020 Feb 26]. Available from: https://www.nytimes.com/2007/11/25/ magazine/25memoir-t.html

40. Boyer A.The undying:What cancer takes away. New Yorker. 2019 Apr 18 [cited 2020 Feb 26].; 28-33.

41. Lenzer J. The danger within us: America's untested, unregulated medical device industry and one man's battle to survive it. New York: Little Brown; 2017.

42. Crowe K. Canadian families stunned by 3,000\% increase in price of lifesaving drug. CBC News. 2018 Mar 10 [cited 2020 Feb 26]. Available from: https://www.cbc.ca/news/health/second-opinion-procysbi-cystagonmarch10-1.4570152

43. Canadian Agency for Drugs and Technologies in Health. Code of Conduct for CADTH Events. Ottawa: CADTH.org; 2019 Jan [cited 2020 Feb 26]. Available from: https://symposium.cadth.ca/code-of-conductfor-cadth-events/

44. Canadian Agency for Drugs and Technologies in Health. CADTH Patient Community Liaison Forum -- Active 2013-2018. Ottawa: CADTH.org; 2020 [cited 2020 Feb 26]. Available from: https://cadth.ca/cadthpatient-community-liaison-forum-active-2013-2018

45. Canadian Agency for Drugs and Technologies in Health. Advisory Bodies: Patient and community advisory committee. Members. Ottawa: CADTH.org; 2019 Jan [cited 2020 Feb 26]. Available from: https://cadth $\mathrm{ca} /$ patient-and-community-advisory-committee

\title{
Pregnancy and severe mental illness: Confounding ethical doctrines
}

\section{JITENDER ANEJA, SONAM ARORA}

\section{Abstract}

Pregnancy brings joy and excitement to some women, but great distress to those who suffer from severe mental illnesses like schizophrenia. Women with severe mental illnesses (SMIs) may have difficulty planning a pregnancy and deciding whether to continue to viability, and thence to term. Dilemmas also surround pharmacotherapy for this population, as (non)treatment is associated with its own challenges. The psychiatrist may have to make challenging decisions based on the principles of autonomy beneficence, and relational ethics. Furthermore, there are ethical controversies inherent to the underlying pathologies, their nontreatment, and the various psychosocial factors that could impact parenting in such mothers. In addition, limited or ineffective use

Authors: Jitender Aneja (anejajitender@gmail.com; corresponding author), Associate Professor, Department of Psychiatry, All India Institute of Medical Sciences, Jodhpur- Romana, Punjab 151001, INDIA; Sonam Arora (asonam2720@gmail.com), Consultant Pathologist, Metropolis Healthcare Limited, Sector-11 D, Chandigarh, 160011 INDIA

To cite: Aneja J, Arora S. Pregnancy and severe mental illness: Confounding ethical doctrines. Indian J Med Ethics. 2020 Apr-Jun;5(2) NS: 133-9. DOI: 10.20529/IJME.2020.037.

Published online on April 16, 2020.

Manuscript Editor: Rakhi Ghoshal

Peer Reviewer: Alok Sarin

(c) Indian Journal of Medical Ethics 2020 of family planning, mental health services, and contraception often act as forerunners of these problems. Considering the sparse literature on this topic and the perplexing legal responsibilities pertaining to the recently implemented Mental Health Care Act, 2017, we have attempted to highlight the various ethical dilemmas that confront a psychiatrist while managing a patient from this group.

Keywords: pregnancy, perinatal, severe mental illness, schizophrenia, psychosis, ethics

\section{Introduction}

Ethical issues and psychiatric practice are the two sides of a seesaw, and are often difficult to balance, with pregnancy adding further complications to this intricate equilibrium. The well-being of a pregnant woman with a serious mental illness (SMI) is influenced by her underlying mental pathology, a plethora of pregnancy-associated psychiatric disorders, and various psychosocial etiological factors. In addition, her unborn child may be affected by the parents' genetic predispositions, pharmaco-treatment, and disrupted parental relationships. In these situations, while catering to the woman and her foetus, the psychiatrist needs to consider the severity of the mental illness, respect her autonomy, and take into account ethical issues. Advances in treatment and the improved sensitisation 
of specialists have led to better patient compliance, improved marital life, and increased responsiveness to family planning in this group. However, most pregnancies among women with SMls are still unplanned (1). When antenatal and postnatal mothers with mental health problems seek psychiatric guidance in managing their pregnancies, it can create dilemmas for the psychiatric team. At times, the psychiatrists are put under duress, as the decision-making responsibility falls entirely on their shoulders (2). With the following case vignette, we raise certain pertinent questions related to perinatal mental health problems and discuss possible solutions.

\section{Case vignette}

A 25-year old married woman who has been on antiepileptics since she was seven years old came in for an antenatal checkup and was referred to the department of psychiatry for symptoms relating to paranoia, lack of self-care, and muttering to herself.

Her condition had started deteriorating during the initial days of her marriage of two years. She was diagnosed with schizophrenia and epilepsy (which has since resolved). She was started on olanzapine with her informed consent and carbamazepine-which she had been taking without a prescription-was tapered and stopped. However, despite counselling her and her family, she dropped out of psychiatric care after two visits, and did not consult psychiatrists elsewhere. Furthermore, weathering the ongoing symptoms of paranoia, she took care of herself, observed precautions for the well-being of her yet-to-be-born child, and experienced limited socio-occupational dysfunction. At term, she delivered a healthy baby girl.

Her psychosis worsened 5-6 months postpartum, and her family brought her back for psychiatric consultation. They cited her movement to another catchment area as the reason for her dropping out, but could not explain her leaving psychiatric care. At the time of her second presentation, she had florid delusions of infidelity, reference, and persecution, along with auditory hallucinations, agitation, poor self-care, marked socio-occupational dysfunction, impaired sleep, and a refusal to eat. She also threatened to commit suicide because of her delusions. The child was being looked after by her mother and sister. In view of the severity of her illness and her lack of mental capacity, she was admitted under supported admission and with the consent of her husband and father. As she refused oral treatment, she was first treated with intravenous haloperidol and promethazine. In the absence of any advanced directives-and given her refusal to eat, severe psychosis, and suicidal threats-we initiated treatment with modified bitemporal electroconvulsive therapy after educating her family and obtaining surrogate consent.

She was lactating at this time and the doctors could not elicit the date of her last menstrual period. During the course of therapy, she was prescribed a pelvic ultrasound for some other indication, and was found to be 12 weeks pregnant. At the time of this revelation, she lacked the mental capacity to understand her situation, and therefore, the medical team told her spouse and family about her pregnancy and obtained revised consent for the continuation of ECT and pharmacotherapy.

Her brief psychiatric rating score reduced from 56 to 22 after four sessions of ECT, and she regained her mental capacity to make decisions for herself. After she learned that she was pregnant for the second time, she was ambivalent about continuing the pregnancy to viability. She expressed concerns about transmitting her illness to her child and the adverse impacts her medication may have on the unborn child. On further follow-ups she almost remitted, with only random ideas of infidelity, but the ambivalence towards continuing the pregnancy remained.

This case raised various questions pertinent to the care of a mother with SMI vis-à-vis her child and her unborn foetus. For the treating team, it entailed certain long-standing but unresolved dilemmas, which we mention below.

1. Should the patient continue or terminate the pregnancy?

2. Can we medicate against the woman's wishes, considering the effects of harmful untreated psychotic symptoms?

3. What are the parenting risks in mothers with SMI?

4. How do we address family planning in women with SMI?

The aforementioned questions are often linked to each other, and thus we will not address their answers in exclusion; rather, we will follow an integrated approach. In the following sections, we attempt to address these important aspects of perinatal mental health in patients with SMI.

\section{Deciding to continue the pregnancy to term}

The twenty-first century saw a revolution in human rights, with rapid advances in women's reproductive rights. We now advocate for the right to reproductive health, including the right to abortions, for all women in most countries. Women with SMIs are more likely to terminate their pregnancies than non-psychiatrically ill mothers $(4,5)$. The factors that motivate this step include a lack of social support, inadequate finances to rear the child, fear of obstetrical complications, fear of parenting with mental illness, and the possibility that the child may be at increased risk of mental illness (6). There has been sparse research on the medical ethics of decisionmaking in the case of pregnant females with SMI. This research is further hampered by different abortion legislations across the globe (7). The last two to three decades have seen some advancements in this field and framing of clinical guidelines and recommendations concerning the identification and management of unwanted pregnancies and the management of pregnancies in patients with SMI (8-10).

The forerunners in this research arena, McCullough et al (11), have proposed an ethical framework for decision-making in cases involving pregnant women with schizophrenia. It consists of five components: (i) chronically and variably impaired autonomy; (ii) assisted decision-making; (iii) surrogate decision-making; (iv) strategies for dealing with the physician's 
feelings in response to these patients, and ( $v$ ) the concept of the foetus as patient. The authors aptly try to balance the principles of beneficence and patient autonomy in the process of decision-making. They state that "respect for autonomy is an ethical principle that obligates the physician to empower the patient's decision-making capacity by providing information about medically reasonable alternatives for the management of the patient's condition" (11). Beneficence is defined as an "ethical principle that obligates the physician to seek the greater balance of clinical goods over clinical harms in the outcomes of patient care" (11). Beneficence-based clinical judgement should be evidence-based. To put it simply, we need to make sure that we keep the patients' right to choose intact, while simultaneously taking the course of action that most benefits them. However, authors like Dudzinski (12) emphasise the patient's autonomy in decision-making. They do not provide enough weightage to the concept of foetusas-patient, and therefore, this model proposes that the woman should take the primary decision to continue or terminate her pregnancy.

McCullough and Chervenak (13) have described a shared decision-making model in which the patient, surrogate (ie a family member/caregiver or a nominated representative), and psychiatrist interact throughout the decision-making process. First, the psychiatrist must ask the patient her beliefs about her condition, diagnosis, prognosis, and alternative management protocols. Next, the psychiatrist must correct factual errors and simultaneously supplement the patient and surrogate's knowledge. They must explain the basis for their clinical judgement regarding all available management protocols, including the wait-and-see approach. With the assistance of the psychiatrist, the surrogate and patient must develop a holistic understanding of her mental condition and the treatment protocols. Finally, they must reach and implement a mutual decision. A recently published international position paper (14) emphasises such a model of decision-making and lays down detailed guidelines to address various aspects of pregnancy-related issues in persons with SMI.

In the Indian context, the Mental Health Care Act, 2017 (or $\mathrm{MHCA}$ ), also recommends respecting the rights of patients and their autonomy in the decision-making processes pertaining to their mental health problems. It also empowers patients with mental illness through the concepts of informed consent and mental capacity. But the MHCA has failed to address the intricate issues of perinatal mental health.

In the above case, at the time of second presentation, the patient had impaired autonomy owing to acute psychosis. The treatment team made attempts to reinstate her mental capacity with the help of pharmacotherapy and biological treatment, both of which they administered with the intention of minimising the impact on the foetus according to the available evidence (15-17).

\section{Pharmacotherapy of pregnant women with psychosis}

Pregnancy often motivates patients to give up prescription medications out of concern for the unborn child (18). The decision to stop or continue pharmacotherapy during pregnancy-often based on various factors like educational level, underlying psychopathology, severity of symptoms, societal pressure, and cultural values-is difficult for any woman. The situation may be further complicated in cases of SMI, which are already plagued by exploitation, victimisation, lack of social support, and compartmentalised delivery of medical health services (10). Although patients with SMI have normal pregnancies and deliveries, they are at increased risk of adverse obstetric outcomes (19). Hence, the question arises: considering the effects of harmful and untreated psychotic symptoms, is it ethical for caregivers and medical professionals to impose treatment against the patient's wishes?

Firstly, as in other decision-making, the general principle is that the patient should be able to decide if she wants to seek treatment and to choose the nature of treatment. The situation gets complicated when a patient with psychosis refuses treatment that the clinician believes is essential $(20,21)$. These ethical concerns are further exacerbated when we apply the principles of relational ethics - that is, when the patient and her baby's well-being are intertwined (22). Relational ethics is defined as "moral responsibility within the context of human relations, [that] recognizes the human interdependency and reciprocity within which personal autonomy is embedded (23). However, we recommend applying this principle without undue coercion or medical paternalism, and with respect for the patient's autonomy, except in situations where it is evident that the benefits of the proposed treatment are clear and overwhelmingly beneficial for the foetus $(5,20)$. But the literature is replete with ethical and legal cases where the previable foetus is not considered a person/patient, and only the mother's autonomy is considered (11).

The Mental Health Care Act, 2017 (3) has various provisions for admission of different categories of patients. It states that only patients with mental capacity (S 4, Chap II) to make decisions can be admitted independently; incapacious patients or those who require high support for decision-making shall be considered for supported admissions (Ss 89, 90). The Act recommends that those under supported admissions be reviewed periodically, and that treating teams seek informed consent from them once they regain their decision-making capacity. Unfortunately, it leaves certain pertinent issueslike the lack of insight, the psychopathology that affects the patient's decisions, and guardianship-unaddressed (24). Also, the situation is murkier if the patient writes an advance directive to not receive certain forms of treatment, viz. electroconvulsive therapy-which could, in fact, be the only form of effective treatment in certain situations, like the one under discussion. However, the American Medical Association (AMA) provides a middle path: it suggests that respectful persuasion and close legal and clinical ethical consultation can guide treating teams through this dilemma.

Secondly, the pharmacotherapy of pregnant women is another grey area, as none of the anti-psychotics have been approved by the US Food and Drug Administration (USFDA) or the 
Central Drugs Standard Control Organisation (CDSCO) for India. The limited data on the safety of various psychotropic medications, antipsychotics included, is available in case reports/series and retrospective studies. Also, research in this population has various ethical and legal ramifications beyond the scope of our discussion. The literature supports the use of second-generation antipsychotics, such as olanzapine, as well ECT in pregnant women with SMI and shows that it does not increase the risk to the foetus in comparison to in healthy pregnant women (15-17). Besides, various professional bodies involved in this field, including the American Congress of Obstetricians and Gynecologists, recommend that pharmacotherapy for SMI during pregnancy be continued for the betterment of the patient as well as her foetus (25).

In the case described previously, even though the treating team educated the patient and her family about her mental condition, they did not follow up or continue with medication during the first pregnancy. At her second presentation, the patient lacked the mental capacity to make decisions about treatment; she appeared to be in a state that was harmful for her as well as the foetus. She was therefore treated after the consent of her family. Once she regained her mental capacity, the treating team sought her consent. However, the big task ahead for the treating team will be to keep her in treatment and deal with the ethical issues pertaining to further treatment as and when they arise.

\section{Parenting risks in mothers with SMI}

A mother with SMI who has recently delivered is at increased risk of developing postpartum psychosis, depression, anxiety, and other child-related disorders. There is a nearly $25 \%$ prevalence rate of postpartum psychosis in women with a prior history of schizophrenia (26), and this is mainly due to discontinuation of prescription medication during pregnancy or lactation (27). Hence, a mother with psychosis/schizophrenia elicits various biases during a physician's assessment of her parenting capacities. Certain research has shown that mothers with SMI have impaired capacity for parenting because of their psychopathology $(28,29)$; studies also show that infantmother interactions are also deficient in this group $(26,30,31)$. The predictors of social service intervention or mother-infant separation include a diagnosis of schizophrenia or other SMI in the mother; low socio-economic status; a psychiatric illness in the partner and a poor relationship with the partner; ethnicity; neonatal complications; previous child or children; singleparent status; and legal problems (32). However, this study mainly incorporated European studies which found a weak association of African-Caribbean ethnicity of mothers with an increased risk of poor parenting outcomes. Furthermore, this association was partly attributed to high prevalence of single parents in African-Caribbean families in comparison to other ethnic groups and that it was also associated with poverty and social class. However, mothers with acute psychosis have shown better mother-infant interactions and lower risks of displacement than mothers with schizophrenia (33). Despite the evidence that most mentally ill mothers do not abuse their children, it remains a significant variable in the history of maltreated children $(34,35)$. Apart from the parent's mental illness, the child's inherent genetic predisposition to suffer from mental illness is a double whammy.

However, ethical principles dictate that one cannot hold women with mental illness to a different standard of parenting than those without mental illness. Laura Miller (36) highlights the dilemma of a physician obliged to look out for the welfare of the "not yet conceived child" whom they believe to be at high risk of maltreatment at the hands of a mother with psychotic illness. According to her, a physician shall attempt counselling the woman about the risks that her mental illness poses to the potential mother-infant relationship. Moreover, women with mental illness must be given access to treatment in the form of psychosocial rehabilitation, parenting skills training, enhanced social support, and other relevant measures in case they conceive. Brockington and others (14) recommend a multi-disciplinary intervention, which should be tailor-made according to the available resources and may include a general practitioner, representatives of obstetric and mental health teams, and social workers, apart from the expectant mother and her family. Only the United Kingdom recognises perinatal psychiatry, which deals specially with perinatal mental health disorders, as a sub-discipline of psychiatry. In other countries, it still awaits recognition among health professionals as well as users. Brockington et al (14) highlight the need for this specialty and propose apt guidelines as well. Disappointingly, no nation has been able to fully address mother-child health needs thus far.

The Mental Health Care Act, 2017 (3) has touched upon this subject briefly by implying that women with SMI receiving care at mental health establishments shall not be separated from their children of less than three years of age. However, if the psychiatrist finds that there is a risk to the child in any form, the child can be separated from the mother, but not for more than 30 days. Nevertheless, as prudent as this may sound, it has failed to address the issue of the child's guardianship in such cases.

In the case of the patient in this study, the concerns that she shared, like the risk of transmission of her illness to her children and the burden of parenting two young children, did put the treating team on shaky ground. However, after the treating team educated her about her illness and highlighted various positive factors, such as the achievement of near-complete remission, the presence of good insight, her adaptive skills, the availability of family support, her financial abilities, and her commitment to engage in further treatment, the patient could make decisions for herself and continue the present pregnancy to term.

\section{Family planning in mothers with SMI}

Mothers with SMI are largely underserved in the area of family planning, and there is very little research on this topic. This population receives limited family planning services because 
of negative attitudes towards their desire for children, lack of knowledge of established guidelines, unwillingness to discuss family planning, and the absence of reproductive autonomy. Many believe that due to a range of factors-particularly the illness, psychotropic medications, and institutionalisationpersons with SMI engage less in sexual activity and have lower fertility than the general population (36). However, de-institutionalisation, provision of community psychiatry services, innovation of newer neuroleptics, and changes in societal attitudes have led more persons with schizophrenia to marry, and thus have increased chances of pregnancy in this group. One of the earliest studies on this from China, which in the 1980s directed people to follow the one-child norm, reported that the rate of birth control was poor in patients with schizophrenia (females more than males) as compared to the healthy population; the author suggested sterilisation as the foremost method of birth control in females with schizophrenia (37).

Some other surveys also revealed that women with SMls did not want to become pregnant, but did not use contraception $(38,39)$. A recent study $(40)$ found that women with mental disorders had an average of three pregnancies, of which two were unplanned. Furthermore, they used less effective methods of contraception. Despite a clear need for family planning counselling in psychiatric settings, it is rarely provided in conjunction with mental health services. Ariela Frieder established guidelines for pre-conception counselling for women with SMl; they cover the identification and treatment of risk behaviour; boosting the patient's knowledge of the risks to mother and child; developing and improving parenting skills; and mobilising support systems (41). A 2009 Indian study from Bengaluru (1) stated that only $18 \%$ of the 135 women registered for a motherchild psychiatry service were referred for pre-pregnancy counselling because of the discordant psychiatrist-patient ratio, unwillingness to disclose pregnancy concerns to a male psychiatrist, and less control of the women over contraception. A decade after this study, and despite recent legislation (MHCA 2017), the situation on the ground remains the same. Although the present MHCA advocates for the rights of mentally ill patients, it has remained silent on the reproductive rights of women with SMIs.

Even though treating psychiatrists often avoid prescribing potentially teratogenic psychotropics to women in the reproductive age group, they often miss out on providing family planning counselling or referring them to an obstetrician for it. Coverdale and others (42) recommend strategies for persons with mental illness to prevent unwanted pregnancies. These include education about resisting unwanted sexual advances, contraception use, the possible benefits and risks of pregnancy, and advocacy of condom use among male partners. A few studies undertaken nearly 50 years ago in some psychiatric hospitals in the US $(43,44)$ emphasised the acquisition of informed consent for contraception, the importance of voluntarism, and the usage of reversible methods of contraception. Although the presently available long-term and reversible contraceptives may prove to be very successful among this population, but their non-removal on request of patients, or utilising coercion or manipulation in view of the principle of beneficence may be outweighed by respect for the patient's autonomy despite an impaired decision-making (8).

\section{Conclusion}

Pregnancy in women with SMls poses challenges to both the patient and the psychiatrist. The underlying psychopathology, pregnancy-induced SMI, pharmacotherapy, and other psychosocial factors make gestation arduous for the patient. On the other hand, respect for autonomy and beneficence, along with numerous ethical and legal issues, create several hurdles for the psychiatrist. Understanding and assessing the patient's decision-making capacity, and the involvement of family members in decision-making throughout pregnancy and intrapartum and post-partum, is the most crucial step in treatment. Thus, psychiatrists need to understand the patient's wishes and explain the available management strategies and her condition to her to reach a mutual decision. This must also be applied postpartum to improve the motherchild relationship and the mother's parenting skills. Further, pregnancies in this study group are often unplanned. Hence, the psychiatrist must educate the patient as well as the partner on the risks that both mother and child face when the mother is on medication while pregnant. Furthermore, they must create awareness about different contraceptive methods in these patients.

\section{Future directions}

Perinatal psychiatry is still an unexplored area of specialisation; it is largely at an infant stage even in developed nations. Lack of public awareness, insufficient mental health services at the grassroots level, and low clinician interest in this area are some of the reasons for an insufficient knowledge base. Despite all the hindrances, a group of researchers have made some progress in this field $(8-10,14)$. Furthermore, the integration of mental health services with other services like social services, child protection, public health, and medico-legal services, is the need of the hour. Like other mental health services, some of these services are highly localised, underdeveloped, and not easily accessible to the common people-especially the Indian population-and often require the patient/caregiver to bear the expenditure (45-47). However, a few centres, like the National Institute for Mental Health and Neurological Services (NIMHANS) at Bengaluru, have been successful in organising such teams. They have been providing perinatal mental health services for more than a decade. The same model may be replicated, at least at some well-developed tertiary care psychiatric centres. Furthermore, the Government of India, through the Mental Health Care Act, 2017, has envisioned the provision of community rehabilitation services for those affected by various mental health problems. So, in the future, this could provide the required manpower to establish perinatal mental services. 


\section{References}

1. Desai G, Chandra PS. Ethical issues in treating pregnant women with severe mental illness. Indian JMed Ethics 2009;6(2):75-7.DOI:10.20529/ IJME.2009.025

2. RamD,GowdappaB,AshokaHG,Eiman N.Psychopharmacoteratophobia: excessive fear of malformation associated with prescribing psychotropic drugs during pregnancy — an Indian perspective. Indian J Pharmacol 2015; 47(5):484-90.DOI: 10.4103/0253-7613.165186.

3. Ministry of Law and Justice, Government of India. The Mental Healthcare Act, 2017. New Delhi: MoL; 2017 [cited 2019 May 15] Available from: https://www.prsindia.org/uploads/media/Mental\%20 Health/Mental\%20Healthcare\%20Act,\%202017.pdf,

4. Miller LJ, Finnerty M. Sexuality, pregnancy, and childrearing among women with schizophrenia-spectrum disorders. Psychiatry Serv 1996; 47(5): 502-6. DOI: $10.1176 /$ ps.47.5.502.

5. Coverdale $\mathrm{JH}$, Turbott $\mathrm{SH}$, Roberts $\mathrm{H}$. Family planning needs and STD risk behaviours of female psychiatric out-patients. Br J Psychiatry 1997; 171:69-72. DOI: 10.1192/bjp.171.1.69.

6. Jablensky AV, Morgan V, Zubrick SR, Bower C, Yellachich LA. Pregnancy, delivery, and neonatal complication in a population cohort of women with schizophrenia and major affective disorders. Am J Psychiatry 2005; 162(1): 79-91.DOI: 10.1176/appi.ajp.162.1.79.

7. Stotland NL. Reproductive rights and women's mental health. Psychiatr Clin N Am 2017; 40:335-40. DOI: 10.1016/j.psc.2017.01.010.

8. McCullough LB, Coverdale J, Bayer T, Chervenak FA. Ethically justified guidelines for family planning interventions to prevent pregnancy in female patients with chronic mental illness. Am J Obstet Gynecol 1992; 167(1): 19-25. DOI: 10.1016/S0002-9378(11)91618-4

9. Coverdale JH, Chervenak FA, McCullough LB, Bayer T. Ethically justified clinically comprehensive guidelines for the management of the depressed pregnant patient. Am J Obstet Gynecol 1996; 174(1): 169-73. DOI: 10.1016/S0002-9378(96)70390-3

10. Babbitt KE, Bailey JK, Coverdale JH, Chervenak FA, McCullough LB. Professionally responsible intrapartum management of patients with major mental disorders. Am J Obstet Gynecol 2014; 210(1): 27-31. DOI: 10.1016/j.ajog.2013.06.024

11. McCullough LB, Coverdale JH, Chervenak FA. Ethical challenges of decision making with pregnant patients who have schizophrenia. Am J Obstet Gynecol 2002 Sep; 187(3): 696-702. DOI: 10.1067/ mob.2002.125767

12. Dudzinski DM. Compounding vulnerability: pregnancy and schizophrenia. Am J Bioeth 2006; 6(2): W1-14. DOI: 10.1080/15265160500506191.

13. McCullough LB, Chervenak FA. Ethics in Obstetrics and Gynecology. New York: Oxford University Press; 1994, pp 278.

14. Brockington I, Butterworth $\mathrm{R}$, Glangeaud-Freudenthal N. An international position paper on mother-infant (perinatal) mental health, with guidelines for clinical practice. Arch Womens Ment Health. 2017; 20(1): 113-20. DOI: 10.1007/s00737-016-0684-7.

15. Kulkarni J, Storch A, Baraniuk A, Gilbert H, Gavrilidis E, Worsley R. Antipsychotic use in pregnancy. Expert Opin Pharmacother. 2015; 16(9): 1335-45.DOI: 10.1517/14656566.2015.1041501.

16. Spodnikova $B$, Halmo $M$, Nosalova P. Electoconvulsive therapy in pregnancy: a review. J Obstet Gynaecol 2015; 35(7): 659-62. DOI: 10.3109/01443615.2014.990427.

17. Calaway K, Coshal S, Jones K, Coverdale J, Livingston R. A systematic review of the safety of electroconvulsive therapy use during the first trimester of pregnancy. J ECT. 2016 Dec; 32(4): 230-5. DOI:10.1097/ YCT.0000000000000330.

18. Bennett IM, Marcus SC, Palmer SC, Coyne JC. Pregnancy-related discontinuation of antidepressants and depression care visits among Medicaid recipients. Psychiatr Serv. 2010; 61(4): 386-391. DOI: 10.1176/ ps.2010.61.4.386

19. Schneid-Kofman $N$, Sheiner $E$, Levy A. Psychiatric illness and adverse pregnancy outcome. Int J Gynecol Obstet 2008; 101(1): 53-6. DOI:10.1016/j.ijgo.2007.10.007

20. Chervenak FA, McCullough LB. Clinical guides to preventing ethical conflicts between pregnant women and their physicians. Am J Obstet Gynecol. 1990; 162(2): 303-7.DOI: 10.1016/0002-9378(90)90374-G.

21. McCullough LB, Chervenak FA, Coverdale JH. Managing care of an intrapartum patient with agitation and psychosis: ethical and legal implications. AMA J Ethics. 2016; 18(3): 209-14. DOI: 10.1001/journalof ethics.2016.18.3.ecas2-1603.

22. Seeman MV. Relational ethics: when mother suffer from psychosis. Arch Womens Ment Health. 2004; 7:201-10.DOI 10.1007/s00737-004-0054-8.

23. Sherwin S. The politics of women's health: exploring agency and autonomy. In: A Relational Approach to Autonomy in Health Care. Philadelphia:The Temple University Press; 2002, p. 19-47.

24. Ali F, Gajera G, Gowda GS, Srinivasa P, Gowda M. Consent in current psychiatric practice and research: an Indian perspective. Indian J Psychiatry. 2019; 61: S667-75. Available from: http://www. indianjpsychiatry.org/text.asp?2019/61/10/667/255577.

25. ACOG Committee on Practice Bulletins-Obstetrics. ACOG practice bulletin: clinical management guidelines for obstetriciangynecologists number 92, April 2008 (replaces practice bulletin number 87 , November 2007). Use of psychiatric medications during pregnancy and lactation. Obstet Gynecol. 2008; 111(4): 1001-20. DOI: 10.1097/AOG.0b013e31816fd910.

26. Bosanac P, Buist A, Burros G. Motherhood and schizophrenic illnesses: a review of the literature. Aust N Z J Psychiatry. 2003; 37(1): 24-30. DOI:10.1046/j.1440-1614.2003.01104.x

27. Wakil L, Perea E, Penaskovic K, Stuebe A, Meltzer-Brody S. Exacerbation of psychotic disorder during pregnancy in the context of medication discontinuation. Psychosomatics. 2013; 54(3): 290-3. DOI: 10.1016/j. psym.2012.07.003

28. Doody GO, Gotz M, Johnstone EC, Frith CD, Owens DG. Theory of mind and psychoses. Psychol Med. 1998; 28(2):397-405.

29. Lyons-Ruth K, Bronfman E, Parsons E. Atypical attachment in infancy and early childhood among children at developmental risk. IV.Maternal frightened, frightening or atypical behavior and disorganized infant attachment patterns. Monogr Soc Res Child Dev. 1999; 64(3): 67-96. https://doi.org/10.1111/1540-5834.00034

30. Snellen M, Mack K, Trauer T. Schizophrenia, mental state, and motherinfant interaction: examining the relationship. Aust $N Z J$ Psychiatry 1999; 33: 902-11.DOI:10.1046/j.1440-1614.1999.00641.x

31. Campbell L, Hanlon MC, Poon AWC, Paolini S, Stone M, Galletly C, et al. The experiences of Australian parents with psychosis: the second Australian national survey of psychosis. Aust N Z J Psychiatry. 2012; 46(9): 890-900. DOI: 10.1177/0004867412455108.

32. Hammond J, Lipsedge M. Assessing parenting capacity in psychiatric mother and baby units:a case report and review of literature. Psychiatria Danubina 2015;27(1):S71-83.

33. Ramsauer B,Achtergarde S.Mothers with acute and chronic postpartum psychoses and impact on the mother-infant interaction. Schizophr Res 2018. DOI: 10.1016/j.schres.2018.02.032

34. Kumar RC. Anybody's child: severe disorders of mother-to-infant bonding.BrJPsychiatry 1997;171(2):175-81.DOI:10.1192/bjp.171.2.175

35. Walsh C, MacMillan $\mathrm{H}$, Jamieson $\mathrm{E}$. The relationship between parental psychiatric disorder and child physical and sexual abuse: findings from the Ontario Health Supplement. Child Abuse Negl 2002; 26(1): 11-22. DOI: 10.1016/S0145-2134(01)00308-8

36. Miller LJ. Ethical issues in perinatal mental health. Psychiatr Clin North Am. 2009; 32(2): 259-70. DOI: 10.1016/j.psc.2009.02.002

37. Xun ML. The problem of birth control in schizophrenic patients. Zhonghua Shen Jing Jing Shen Ke Za Zhi 1986;19(6):335-8.

38. Berman C, Rozensky RH. Sex education for the chronic psychiatric patient:the effects of a sexual-issue group on knowledge and attitudes. Psychosocial Rehabilitation Journal. 8(1): 28-34. DOI: 10.1037/h0099646

39. Coverdale $\mathrm{JH}$, Aruffo JA. Family planning needs of female chronic psychiatric outpatients. Am J Psychiatry. 1989; 146(11): 1489-91. DOI: 10.1176/ajp.146.11.1489

40. Hauck $Y$, Nguyen T, Frayne J, Garefalakis M, Rock D. Sexual and reproductive health trends among women with enduring mental illness: a survey of Western Australian community mental health services. Health Care Women Int. 2015; 36(4): 499-510. DOI: 10.1080/07399332.2014.973957.

41. Frieder A.Pre-conception counseling for women with schizophrenia.Curr Women's Health Rev. 2010; 6:12-6. DOI: 10.2174/157340410790979680

42. Coverdale J, Balon R, Beresin EV, Brenner AM, Guerrero APS, Louie AK et al. Family planning and the scope of the "Reproductive Psychiatry" Curriculum. Acad Psychiatry. 2018; 42(2): 183-88. DOI: 10.1007/s40596018-0884-8 
43. Grunebaum $\mathrm{H}$, Abernethy V. Ethical issues in family planning for hospitalized psychiatric patients. Am J Psychiatry. 1975; 132(3): 236-40. DOI:10.1176/ajp.132.3.236

44. Abernethy V, Grunebaum $\mathrm{H}$. Toward a family planning program in psychiatric hospitals. Am J Public Health. 1972; 62(12): 1638-46. DOI:10.2105/ajph.62.12.1638.

45. Raykar N,Nigam A, Chisholm D. An extended cost-effectiveness analysis of schizophrenia treatment in India under universal public finance. Cost Eff Resour Alloc. 2016; 14(9). DOI 10.1186/s12962-016-0058-z.
46. Selvaraj S, Farooqui $\mathrm{HH}$, Karan A. Quantifying the financial burden of households' out-of-pocket payments on medicines in India: a repeated cross-sectional analysis of National Sample Survey data 1994-2014. BMJ Open. 2018; 8: e018020.DOI: 10.1136/bmjopen-2017-018020.

47. Mathias K, Shukla A, Jacob KS. "We sold the buffalo to pay for a brain scan"-a qualitative study of rural experiences with private mental healthcare providers in Uttar Pradesh, India. Indian J Med Ethics. 2019; 4(4)NS: 282-7. DOI: 10.20529/IJME.2019.057.

\section{Administering drugs to an individual in a non-pathological situation: The Caster Semenya case}

\section{JAGADEESH N}

\begin{abstract}
The International Association of Athletics Federations (IAAF) has barred individuals whose circulating testosterone levels are higher than $5 \mathrm{nmol} / \mathrm{L}$ from competing in women's competitions in middle-distance track events. To become eligible, they must take anti-testosterone treatment to achieve the appropriate testosterone levels. The 2019 decision of the Court of Arbitration for Sport has brought the spotlight back on Caster Semenya's case and on the ethics of testing the testosterone levels of sports persons with or without consent, imposing anti-testosterone treatment in order to qualify to participate in sports competitions for females. This article debates all the issues concerned from various perspectives.
\end{abstract}

Keywords: Testosterone levels, intersex variations, DSD, IAAF rules, sex verification tests, anabolic effects.

\section{Background}

Caster Semenya is a South African Olympic athlete who was asked by the International Association of Athletics Federations (IAAF) in 2009 to undergo sex verification tests to prove herself female. She was prevented from competing in world athletics events till the IAAF deemed her eligible to compete in 2010. The Caster Semenya case is in the news again (1); but this time the medical community is also involved in the debate. The Court of Arbitration for Sports (CAS) upheld the IAAF regulation $(1,2,3)$ that individuals must have testosterone levels below $5 \mathrm{nmol} / \mathrm{L}$ to compete as females. Otherwise, they

Author: Jagadeesh N (forensicjagadeesh@gmail.com), Professor and Head Department of Forensic Medicine and Toxicology, Vydehi Institute of Medical Sciences and Research Centre, Whitefield Road, Bengaluru 560066 INDIA.

To cite: Jagadeesh N. Administering drugs to an individual in a nonpathological situation: The Caster Semenya case. Indian J Med Ethics. 2020 Apr-Jun;5(2) NS: 139-43.DOI: 10.20529/IJME.2020.030.

Published online on March 21, 2020.

Manuscript Editor:Vijayaprasad Gopichandran

Peer Reviewers: An anonymous reviewer

(c) Indian Journal of Medical Ethics 2020 must take treatment to lower their testosterone levels. This brings us to a debate on several ethical issues.

What is the available research evidence on the issue of testosterone levels and their impact in sports persons having DSD (Differences in Sex development)?

Testosterone levels improve individuals' anabolic effects, muscle building abilities, and confidence levels (4). Whenever there are higher levels of circulating testosterone in a female with properly functioning androgen receptors, there is a definite increase in muscle mass and muscle strength, circulating haemoglobin levels, and thus, sporting potential (3). Hence, IAAF has restricted the eligibility to compete in women's competitions based on circulating testosterone levels to remove any unfair advantages in the $400 \mathrm{~m}$ to one mile middle distance track events (5). It also specifies waiting for a six-month period after the administering of antitestosterone treatment to remove any residual effect of the high testosterone levels $(2,3)$ in sports persons with DSD.

\section{Are all individuals with DSD or hyperandrogenism barred from all sports competitions?}

As per IAAF guidelines, individuals with differences in sex development (DSD) or hyperandrogenism are not barred from all sports competitions. The IAAF has clarified (2) that only for international competitions, individuals with the following DSD are barred from competing in the female category in distance track events (400 $\mathrm{m}$ to a mile distance) in both individual and relay competitions: $5 \beta$-reductase type 2 deficiency, partial androgen insensitivity syndrome (PAIS), 17 $\beta$-hydroxysteroid dehydrogenase type 3 (17 $\beta$ - HSD3) deficiency, ovo-testicular DSD, any other genetic disorders involving disordered gonadal steroidogenesis. In addition, to be barred, individuals with DSD should have circulating blood levels of testosterone above 5 $\mathrm{nmol} / \mathrm{L}$ and sufficient androgen sensitivity for the testosterone levels to have a material androgenising effect. Female athletes exhibiting hyperandrogenism (polycystic ovarian syndrome and androgen insensitivity syndrome) (3) are not barred, as their circulating blood levels of testosterone are below 5 $\mathrm{nmol} / \mathrm{L}$. This standard of $5 \mathrm{nmol} / \mathrm{L}$ could be because of IAAF 